\section{Managing Copyright Services at a University}

\author{
Donna L. Ferullo, Guest Columnist \\ Correspondence concerning this column should be \\ addressed to Marianne Ryan, Associate University \\ Librarian for Public Services, Northwestern University \\ Library, 1970 Campus Drive, Evanston, IL 60208; \\ e-mail:marianne-ryan@northwestern.edu.
}

Donna L. Ferullo is Director, University Copyright Office, Purdue University, West Lafayette, Indiana.
Within the academic library community, copyright is an area of critical importance and growing interest. As the landscape of information creation and delivery continues to change, interpretation of existing copyright guidelines, including Fair Use, has become less clear, and new laws have been passed. Scholarly communication issues, involving digital collections, institutional repositories, and consortial agreements are among the many evolving areas—along with authors' rights-that require copyright awareness and support. As a result, many campuses are establishing copyright offices, often within their libraries. Such services are invaluable to their constituents. In the following article, Donna Ferullo shares some of her experience in managing a university copyright office. She also offers insight to other institutions that may be considering providing such a service._-Editor

I

n 2000 I was appointed the first director of the newly created University Copyright Office at Purdue University. I was presented with a blank canvas, which was exhilarating but at the same time daunting. Where to start? I decided to first look at how and why the office came into being and then survey the copyright environment within the university. This was an invaluable exercise since it provided me with the necessary information to decide what services were needed and how to implement them. The following is the information I discovered during that exercise and throughout the years since, as well as my observations as to the questions that need to be asked. Over the past eleven years, the core purpose of the office has not changed, but certainly the approach and structure has, given the fluidity of copyright law and its application.

Copyright is big business, and many universities are discovering that their infrastructure does not support an effective and efficient way of not only responding to copyright problems but also managing copyright as well. When did copyright become big business in education? Why is it so important, and how did it become part of the everyday vocabulary at universities? How can universities address copyright issues?

In the past, copyright at universities was perceived as being primarily associated only with faculty in terms of the copyright in their own works and using other people's copyrighted works in the classroom. Traditionally, universities have differed from other businesses by allowing some of their employees, such as faculty, to retain copyright to the works they create while employed at the university whereas ownership of the copyright in works created by staff follows the traditional business model of the university owning the copyright. 


\section{MANAGEMENT}

The copyright environment really began to change as technology became more advanced. Computers made it easy to copy and distribute copyrighted works, which caused content holders to become quite controlling of their works. As they became increasingly protective and restrictive in the use of their works, universities became more concerned and aware of the impact such restrictions would have on education. The exceptions in the U.S. Copyright law, particularly fair use and the education and library exceptions, became even more critical to achieving the mission of education. However, many universities did not understand the exceptions and how to apply them or they were being interpreted incorrectly and being applied inconsistently across campus.

At the same time that technology was making rapid advancements and significant changes, Congress was being heavily influenced by major content holders such as the movie, music and publishing industries to narrow the scope of the use of copyrighted works. This created the perfect copyright storm. The copyright landscape shifted dramatically starting in the 1990s with the drafting and eventual passage of three key pieces of copyright legislation: the Digital Millennium Copyright Act of 1998 (DMCA); the Copyright Term Extension Act of 1998 (CTEA); and the Technology, Education and Copyright Harmonization Act of 2002 (TEACH). The DMCA provides universities with the option to be classified as online service providers with limited liability should users of their computer network infringe on a copyright. The CTEA added another twenty years to the duration of copyright, which meant that works would be protected for a longer period. TEACH changed the way copyright applies to distance education and course management systems by allowing the digital transmission of copyrighted works but with many requirements and restrictions. The confluence of those three amendments to copyright law and ever changing technologies made some universities really sit up and take notice of how copyright was handled at their institution.

Administrators originally identified the copyright problem as two-fold and structured their actions accordingly. The first was in response to the DMCA. Designated agents as defined under the DMCA were appointed to address official notices of copyright infringement by users of the university computer network. The second was drafting copyright policies, which varied greatly across institutions. Many institutions developed policies after the passage of TEACH, since having a copyright policy is one of the requirements of the amendment if institutions want to take advantage of that exception in the copyright law. These efforts were mostly to protect the universities, which was all well and good, but faculty and particularly librarians saw that the issue was much broader and that it impacted the way educators do business. Librarians became advocates on their campuses to have copyright discussions at all levels of the university. These discussions generated partnerships with Provosts and other senior administrators. Institutions approached the copyright dilemma in a variety of ways, and several established copyright offices. The first such office in the country was the Copyright Management Center at Indiana University in Indianapolis, spearheaded by Kenny Crews. There are now many other such offices at universities with varying levels of authority and scope.

On the surface, establishing and managing a copyright office sounds simple enough but there are many complex layers that require much planning and thought. When creating such an office, many questions need to be answered before someone can be hired to lead it. To begin, administrators need to take inventory and ask some basic questions such as: How is the university handling copyright issues? Is there a well-structured plan in place to deal with copyright? Is there a copyright policy? If so, what does it cover? If not, should one be developed and what is the scope of coverage? Is there a designated person or people on campus to turn to when copyright questions arise or is it someone who has the unofficial job by default, typically a librarian? What copyright questions are being asked on campus? The next level of questions to be answered revolve around the office itself. These include: What is the role of the office? What is the role of the director? Where does the office reside administratively? Will the office respond to inquiries only from the university or from the broader community as well?

Initial discussions of whether a copyright office is needed on campus has to take into account all stakeholders' interpretation and definition of copyright, since it can mean different things to different people. The differences are usually determined by the status of the individual within the university. Many times there is a lack of understanding and interest in copyright until a situation occurs. Generally, though, faculty are concerned about copyright in the works they create and what they can use in the classroom and through course management systems. Also, copyrightability of data are currently one of the major hot button issues for faculty. Technologically it's easy to use copyrighted works in a variety of ways, but it's not necessarily always legal. Faculty are becoming more aware of the pitfalls and seek guidance as how to accomplish their educational objectives and still remain within the letter and spirit of the law. Graduate students have similar concerns to those of faculty. Undergraduates are typically not concerned, but they are aware that peers are being sued mostly by the recording industry for downloading and sharing music. Their attitude is more along the lines of catch me if you can. Administrators assess copyright from all angles such as stewardship of university copyrights to supporting employees' use of copyrighted works to the fullest extent allowed by law. Staff create copyrighted works and also assist others with the use of protected works. Librarians have numerous copyright issues ranging from preservation to sharing materials. Understanding the wide range of copyright issues and the level of copyright knowledge in the university community provides a good foundation for structuring the next steps.

A survey of how copyright concerns are currently being handled on campus is very important. It is critical to understand all the players and how they contribute to the overall mission. If there is in house legal counsel, then it becomes a 
priority to discuss how knowledgeable their attorneys are in copyright law and what level of involvement they have and are able to have in resolving day-to-day issues. In response to the passage of the DMCA, many universities appointed DMCA agents who reside in various positions throughout the university. They handle copyright complaints, so their input is needed as well. Another area of the university that generally has some type of copyright responsibility is the technology transfer office. Many times such offices are more interested in seeking out and managing patents for the university, but they are usually also charged with managing the copyrights owned by the university. Offices on campus that review contracts for the university, such as a purchasing department and research grants departments, have many copyright issues. Information technology departments deal with copyright issues all the time. Mostly they are in the business of drafting and enforcing computer use policies, but the security issues with copyright are significant as well. Librarians respond to copyright inquiries and are sometimes regarded as the copyright experts on campus, especially when there might not be a designated copyright office or in- house legal counsel with copyright expertise. Librarians are in a unique position at universities because they are trusted resources on campus and have access to all colleges/schools/departments within a university. All of the above are parts of a copyright jigsaw puzzle that must fit together to provide comprehensive copyright services.

In many cases, the role of a copyright office can be defined by university policies. Copyright offices can be focused on responding to issues arising from the use of copyrighted materials and/or determining ownership of copyrighted materials created at the university. Most universities have policies on the copyright ownership rights of employees, and some have use policies. There can be two separate policies or one policy that attempts to cover both ownership and use. Having a policy or policies certainly provides a starting point when developing an action plan, which might include establishing a copyright office, to address the myriad of copyright issues that arise on campus. Even if there are two separate policies on ownership and use with separate offices to address each, they are not mutually exclusive and there can be much overlap.

Determining the purpose and scope of a copyright office as well as what services it will offer can be difficult. When defining the purpose of the office, one must take into account how the office will fit within the infrastructure of the university. What will be the relationship of the office with the other entities on campus that also provide some type of copyright services? Will they remain separate areas, or will they all be merged and under the auspices of the new office? If they remain separate, then who has the authority to do what and is there some type of senior oversight and coordination? There are many different models, but the services can include advising and educating the university community, promoting awareness of rights and responsibilities under the copyright law, and monitoring copyright legislation, case law and developments in the world of copyright. Another significant decision that needs to be made in this context is the scope of authority that the office will have on campus. Does the office have the authority to speak on behalf of the university? Will the office provide official legal advice or legal information?

Identifying the constituents the office will serve and the scope of issues to be addressed can be a challenge. Will the office work only with administrators, faculty, and staff or with students as well? Students, if not employees of the university, have a different legal relationship with the institution. If students are being considered for inclusion, will there be different levels of support based on the classification of student, such as graduate vs. undergraduate? The scope of issues can vary from interpreting and applying fair use to reviewing publishing agreements.

It is imperative to have a mandate for the office with the boundaries and parameters clearly articulated. However, even when that occurs, there are always gray areas. The law of copyright does not exist in a vacuum. Many times there are numerous legal issues incorporated within a copyright question. Contracts can go hand in hand with copyright issues, from licenses that the library signs to provide resources to the campus to publishing agreements that faculty and graduate students need to negotiate with publishers. Copyright is part of a larger body of intellectual property law, which also includes trademarks and patents. Questions on trademark are often part of the copyright equation, as are rights of publicity and privacy.

Once the services and scope have been defined, that will determine the necessary credentials of the director. The credentials of a director of a copyright office or the person assigned the responsibility of responding to copyright inquiries varies by university. The three most common credentials are a master's degree in library science, a law degree, or a combination of the two. If the director does not have official legal authority for the campus, then many times they are in a quasi-legal role. Another decision that needs to be made is whether or not this position is a faculty position or a purely administrative one.

Depending upon the university, the copyright office or the person designated to respond to copyright inquiries can be physically and administratively located within the library, the Provost's office or the legal counsel office. Much depends upon the classification and rank of the individual.

Once a copyright office has been established, then decisions on what services to provide and how to provide them need to be made. A web presence is always very helpful, as are handouts such as brochures and fact sheets. Networking and establishing liaisons across campus is extremely beneficial. Requests for advice and consultations occur via e-mail, telephone, or in person $24 / 7$, so structuring a response system will facilitate such requests. Have a list of referrals for those areas that might overlap with copyright but are not within the purview of the office. Maintaining statistics on the number of questions received and categorizing them by type of question responded to (basic copyright, converting works to digital, fair use, classroom and teaching issues, research) helps to formulate strategies for future direction of the office. 


\section{MANAGEMENT}

The message of the office is important as well. Under pressure from content holders, there are some universities or departments within universities that focus on what can't be done under the copyright law. It's certainly understandable given their role within the university. However, it's just as important and sometimes even more so to have the office focus on what can be done. The goal is to provide quality service to the users so that they can fulfill their university's educational mission.

A wide range of questions are received by copyright offices. Very few are simple, and the majority involve multiple issues that are not always strictly copyright related. I have seen two areas where the number of questions in recent years has skyrocketed. The first revolves around author rights. Universities are trying to encourage their faculty to manage their copyrights so that they can use their works in ways such as posting to an institutional repository, using them in future publications, and distributing to students and colleagues. The second area that is growing by leaps and bounds is copyright issues associated with mass digitization projects. They range from the Google Book project to HathiTrust to institutional repositories.

Over my tenure as director of a copyright office, copyright laws have changed and major copyright decisions have been handed down by the courts. There also has been a turnover in many senior administrative positions within my university which changed the focus of the university and caused a shift in the university's culture. However, what has not changed is the complexity of copyright and the need for copyright expertise on campus. A university copyright office provides an invaluable service to its users. 